\title{
An Analysis on Total Factor Productivity and Influencing Factors of Soybean in China
}

\author{
Mingming Liu (Corresponding author) \\ College of Economics Management, Sichuan Agricultural University \\ No.36, Xing Kang Road, Ya'an City, Sichuan Province 625014, China \\ E-mail: hnlm.1986@163.com \\ Dongmei Li \\ College of Economics Management, Sichuan Agricultural University \\ No.36, Xing Kang Road, Ya'an City, Sichuan Province 625014, China \\ E-mail: cndldm@163.com
}

\begin{abstract}
To investigate the characteristics of total factor productivity and its influencing factors in china's soybean. Cobb-Douglas production function model is used in this study. The data is based on the period from 1990 to 2007, and C-D production function is applied twicely. The results of this study indicate that total factor productivity grows at $0.42 \%$ annually, the changes fluctuate apparently. Through analysis, the pattern of cultivation, imports and exports policy and technical achievement may contribute to the fluctuation of total factor productivity in China's soybean. Finally, the study proposes some approaches and policy implications so as to increase the production of soybean.
\end{abstract}

Keywords: Soybean, Cobb-Douglas production function, Total factor productivity, Influencing factors

\section{Introduction}

Soybean is not only grain crop, but also economic crop. It is the main source of protein, oil and feed. China was the biggest country in the world before 1950s, when china's soybean yield and trade volume ranked first in the world, ninety percent soybeans were supplied by China. However, China had begun to change from soybean exported country to imported country since 1996. As statistical datas displayed, in 2006, the import volume of chinese soybean was 28236.69 tons, while the export volume was only 37.90 tons. There was serious short supply in domestic, China had lagged far behind some countries such as America and Brazil, and so on. Therefore, stabilizing and developing domestic soybean's yield are important to guarantee the demand of edible soybean and to keep the market shares.

At present, the growth of soybean yield depends on three aspects. The first one is to enlarge planting areas, the second one is to increase the input of material factors, and the third one is to raise productivity gradually. Due to the limitations of planting areas and the input of material factors, we can't only depend on the increasing material factors, especially under the background that planting areas are declining and agricultural production structure is adjusting. Hence, raising productivity has an important effect on the growth of soybean yield. In this paper, Therefore, investigating the characteristics of total factor productivity in chinese soybean and analyzing its influencing factors can contribute to the growth of soybean production, it helps us to clearly define what growth mode and technical progress policy we should choose. They are of great practical significance to increase the soybean yield and guarantee the food security.

Now, many experts at home and abroad researched the production ability of soybean with different angles and methods. Dwight R Sanders and Mark R Manfredo (2006) used the 5-year average as the benchmark method with ARMA and VAR models to forecast basis levels in the soybean futures complex: soybean, soybean meal and soybean oil. The forecast evaluation results suggested that alternative naive techniques may produce better forecast, and the improvement gained by time series modeling is relatively small. Jorge Fernandez-Cornejo (2002) estimated the on-farm impacts of adopting herbicide-tolerant soybean on herbicide use, yields and farm profits through an econometric model, using nationwide farm-level survey data for 1997. Philip M. Fearnside (2001) considered that Brazil produced just under one-quarter of the global soybean harvest in 1998. However, 
Brazil still needed lots of infrastructure projects and thought of the social and environmental factors. H.Van Den Berg and A.S Lestari (2001) conducted the 86 replicated experiments on soybean cultivation practices in eight provinces to identify local differences in the effects of cultural practices on yield. It is suggested that farmers need training in how to improve their cultural practices and that it should utilize locally conducted field experiments.

Wei Tian and Mingxian Li (2009) used Non-parameter Malmquist index method to decompose the efficiency changes of soybean production. The results showed that the growth of soybean TFP was mainly promoted by the technical change. Jianbin $\mathrm{Yu}$ (2007) used the panel data from 1990 to 2004 in 11 provinces to study the technical progress and technical efficiency in chinese soybean and to explain the main influencing factors with the method of logarithmic function. Cuiling Yu and Zhongchao Feng (2005) adopted Cobb-Douglas production function to calculate the contribution rate of land, capital and policies in China's soybean output. The results showed that capital cintributed the most to China's soybean output, followed by land, while the effect of policies and systems over the same period was negative. Wu Huang and Kai Wang (2004) measured the technical efficiency and its determinants of soybean production in soybean producing provinces through a stochastic frontier production function model. Fu Qin, Lixin Sun and Renpu Bai (2003) used the method of RCA to analyze the competitiveness of China's soybean industry. They believed that soybean have greater potential comparative advantage among the four major crops in China. Jimin Wang (2000) analyzed the relationship between soybean input and output through the Cobb-Douglas production function. The results suggested that planting areas, labor, chemical fertilizer, other materials and disater rate have a remarkable influences on the soybean yield.

Based on the previous studies, the paper calculates the total factor productivity in chinese soybean over the period 1990-2007 using Cobb-Douglas production function model twicely, and analyzes the influencing factors of soybean TFP.

\section{Materials and methods}

\subsection{Soybean TFP}

\subsubsection{Data}

Data for the study was based on time-series data from 1990 to 2007. Considering the availability of the whole data and the different roles of input factors in soybean production, and to better reflect the economic benefits of soybean production. Besides, to exclude the impact of price changes in differenr years, we'd better use the quantitative indicators, the tatal output, capital, labour and land are adopted in the paper. Specific instructions are listed as follows:

Soybean output is reprensented directly with the soybean yield, which can be derived from "Statistical Yearbook of China's rural areas".

The data of soybean input. Capital is expressed by the total materials expenses, including direct costs and indirect costs. Moreover, direct costs contain seed costs, fertilizer costs, pesticide costs, lease operating expenses, fuel and energy costs, repair and maintenance costs and so on. Indirect costs contain assets depreciation, insurance, management fees, financial fees and selling expenses. In order to eliminate the impact of price, in the model, we have amended the data with agricultural production price index, which comes from "China Price Statistical Yearbook". As for the labor input of soybean, there isn't specific statistic data, "National Agricultural Costs and Returns Compilation of information" only provides the cost-benefit data of labor per unit area. Therefore, the labor input is the days of labor multiplied by soybean acreage. Land input is expressed by the total acreage of soybean, which can be obtained from the "Statistical Yearbook of China's rural areas".

\subsubsection{Methodology}

Total Factor Productivity (also can be called TFP for short) is a common indicator used to measure productivity, it is also an important means in analyzing the source of economic growth. In 1957, Solow decomposed the growth of output into growth of capital, labor, and technological progress in his article named as "Technical change and aggregate production function", and proposed Solow residual value method, which was later widely used to measure technical progress and analyze the source of output growth.

In the paper, Cobb - Douglas production function is used, and the formula is showed as below:

$$
\mathrm{Y}=\mathrm{AK}{ }^{\alpha} \mathrm{L}^{\beta} \mathrm{M}^{\gamma}
$$

Where $\mathrm{Y}$ indicates soybean yield, $\mathrm{K}$ indicates labor input, $\mathrm{M}$ indicates planting areas. And $\alpha, \beta, \gamma$ are respectively the elasticity coefficients of capital, labor and planting areas. In order to facilitate the regression, in fact, the regression equation is the logarithm form. We can get it like this: 


$$
\ln Y=\ln A+\alpha \ln K+\beta \ln L+\gamma \ln M
$$

According to the definition of TFP, It is obtained that:

$$
\mathrm{A}=\mathrm{Y} /\left(\mathrm{K}^{\alpha} \mathrm{L}^{\beta} \mathrm{M}^{\gamma}\right)
$$

According to Solow residual value method, the growth of TFP can be drawed as:

$$
\hat{a}=a / y * 100 \%
$$

Where â is the rate of TFP.

\subsection{The influencing factors of soybean TFP}

\subsubsection{Inluencing factors of soybean TFP}

Based on the analysis above, we further research the influencing factors of soybean TFP. Through reading literatures, we find that R\&D of new varieties is an important indicator reflecting TFP of China's soybean. A large number of emergences of new soybean varieties will increase the technical content of soybean and make farmers' production behavior more scientific and rational. Import and export trade reflect the competitiveness of China's soybean in the international market. Only through participation in international competition, should deficiencies in China's soybean production be better identified. We should make full use of WTO rules to recommend the advanced production and processing technologies, so as to raise TFP of China's soybean. Increasing the proportion of soybeans in the crops appropriately, changing agricultural planting structure and optimizing the allocation of resources provide necessary conditions for soybean to research and apply advanced production technology. Policies and systems have always been the key influencing factors, especially in the application of agricultural production, the government's preferential policies and subsidies to rural areas and farmers directly affect the structure of agricultural production, as well as the farmer's production enthusiasm.

Based on the previous studies, combined with the actual situation of China's soybean production, the factors such as technical achievement, imports, the pattern of cultivation, and policy are considered in the paper. The variable of technical achievement is the number of authorized vatieties annually, it is defined as $\mathrm{X}_{1}$, which can be obtained from " List of National validated varieties of crops ". Import and export trade is the imported volume of soybean with $\mathrm{X}_{2}$, directly from "China Rural Statistical Yearbook". The pattern of cultivation is the proportion of soybeans in the crops, it is defined as $\mathrm{X}_{3}$. The variable of policy is expressed by the average price of soybean, it is approximately defined as $\mathrm{X}_{4}$, which has been amended by production price index over the years.

\subsubsection{Introduction of model}

According to C-D production function, considering $\mathrm{X}_{1}, \mathrm{X}_{2}, \mathrm{X}_{3}, \mathrm{X}_{4}$ work separately on TFP, we can define TFP as dependent variable and establish the model as follows:

$$
\mathrm{TFP}=\lambda \mathrm{e}^{\mu} \mathrm{X}^{\beta 1} \mathrm{X}^{\beta 2} \mathrm{X}^{\beta 3} \mathrm{X}^{\beta 4}
$$

Where $\mathrm{e}^{\mu}$ is disturbance, $\beta_{1}, \beta_{2}, \beta_{3}, \beta_{4}$ are respectively the elasticity coefficients of the four influencing factors of TFP.

\section{Results and discussion}

\subsection{Calculation and analysis of soybean TFP}

\subsubsection{Test of stationarity}

Before regression, in order to avoid fake regression, we should test the stationarity of the logarithmic series in the model with the method of ADF. The results suggest that the logarithmic series of planting areas, material costs and labor are unsteady. But they become steady after the differential transition, which meets the demand of regression( Table 1).

\subsubsection{Regression analysis}

According to type (2), and statistical software Eviews3.1 is adopted. It is obtained that:

$$
\begin{aligned}
& \ln \mathrm{Y}=-0.89+0.40 \operatorname{lnK}-0.08 \ln \mathrm{L}+0.68 \ln \mathrm{M} \\
& \begin{array}{llll}
(-0.55) \quad(3.59) \quad(-2.20) \quad(3.06)
\end{array} \\
& \mathrm{R}^{2}=0.92 \quad \mathrm{~F}=52.48 \quad \text { D.W. }=2.48
\end{aligned}
$$

As can be seen from the results, $\mathrm{R}^{2}$ is 0.92 , which shows that simulation effect is perfect. All the variables have passed the T-test. Meanwhile, the probability accompanied by $\mathrm{F}$ is 0.0000 , it shows the high linear between variables, the regression equation is remarkable. At the significance level of $5 \%, \mathrm{D} . \mathrm{W} .>\mathrm{d}_{\mathrm{u}}=1.69$ (sample size is 18). There isn't autocorrelation among the residual series according to statistical decision method. Followed by 
material costs and labor, with the elasticity coefficients are 0.40 and -0.08 . It can be seen from the elasticity of input-output, the coefficient of planting areas is the biggest with 0.68 . It is suggested that when planting areas increase per unit, the output will increase 0.68 units, when the material costs increase per unit, the output will increase 0.40 units on average. The role of labor to output isn't obvious, even is negative. The output increases while the number of labor input is declined. That is, with the economic development and technological progress, The capital takes instead of labor gradually.

\subsubsection{TFP and the growth of TFP}

Put the value of $\alpha, \beta, \gamma$ into types (3), (4). Finally, we can obtain the value of TFP and the growth rate of TFP from 1990 to 2007 (Figure 1).

As can be seen from figure 1, TFP is relatively stable, the growth rate of TFP fluctuates greatly, but it is consistent with the growth rate of soybean yield. The growth rate of TFP is only $0.42 \%$ over years. In 1990, 2003, and during the period between 1994 and 2000, the growth rate of TFP is negative, its efficiency is far low. Because our country neglect the importance of soybean production, compared to rice, wheat, corn and other main crops, there is not protective price of soybean, and the expense of R\&D is low. For example, the plan of Grain Yield Engineering doesn't include soybean, which leads to the slow growth of soybean yield, the fluctuation of planting areas and the increasing of import. China's soybean production is still dependent on increasing material input and enlarging the planting areas.

\subsection{The results and analysis of factors influencing soybean TFP}

Firstly, we test the stationarity of logarithmic series and logarithmic difference series in the model with the method of ADF. The results suggest that all the logarithmic series are unsteady. But they become steady after the differential transition, which meets the demand of regression. According to type (5), the regression results can be obtained (Table 2).

As can be seen from the regression results, the model fits well, all variables have passed T-test. The elasticity coefficients of four variables are not big. That is, the contradiction of cultivation structure, policy suppression, and the import extrusion for soybean in domestic and other factors affect the enthusiasm of farmers. The adoption of new technology and new varieties is prevented, which leads to the fluctuation of soybean TFP, even stagnation.

Elasticity coefficient of technical achievement is 0.0015 . It is suggested that when the input of technical achievement increases $1 \%$, soybean TFP will increase $0.0015 \%$. In recent years, china has bred many new varieties, but the quality of the varieties is still far from the varieties on the international market. So we should focus on breeding high-oil, high-yield, early-maturity and high-quality varieties to meet the market demand. In some remote mountainous areas, there are poor transport facilities, economic backwardness, low educational level farmers. Hence, new varieties and new technologies may not be promoted timely, technology and information dissemination are slow too, inputs are seriously short, all these result in low yield of soybean.

Elasticity coefficient of import volume is negative, that is, it has negative impact on soybean TFP. All along, China has not quantitative restrictions to imports of soybeans and soybean meal, and the tariffs are very low, only $3 \%$ of soybean import tariffs, $13 \%$ of the value-added tax. On one hand, China imports large quantities of soybeans. On the other hand, there is overstocking of soybean in domestic. International soybean has a serious impact on domestic soybean such as planting, production, processing, etc., which leads to the reduction of planting areas in china's soybean. China has been taken placed by America, Brazil and Argentina. In addition, cost advantages are apparent in those countries, which also makes the imports of China's soybean continue to increase.

Elasticity coefficient of the pattern of cultivation is 0.0350 . That is, when the pattern of cultivation increases $1 \%$, soybean TFP will increase $0.0350 \%$. If we want to enlarge the planting areas, we will reduce the planting areas of rice, wheat, corn and other main crops. But it is unrealistic. It is impossible that soybean becomes the key point instead of rice, wheat and corn.

Elasticity coefficient of policy is 0.0097 . That is, when the policy increases $1 \%$, soybean TFP will increase $0.0097 \%$. The price of soybean fluctuates sharply, such as in 1999 and 2001, when there is a substantial decline. As a whole, the price of soybean is still upward. However, China's protective measures to soybean is still insufficient, it has yet to formulate protective price of soybean.

\section{Conclusions and implications}

Through the analysis and study above, the main conclusions and suggestions are obtained as follows. 
During the 18 years, from 1990 to 2007, the average growth rate of China's soybean TFP is only $0.42 \%$. Seen from different periods, from 1994 to 2000, in the year 1990 and 2003, TFP growth of China's soybean is negative. However, in 2004, it restored again. The results show that the changes of soybean TFP is basically in accordance with the adjustment of China's policies. The contradictions of planting structure in new stage have a negative impact on soybean TFP.

Based on the elasticity of input factors, planting area is the biggest influencing factor in the four input factors of soybean production, the second is the material cost, while the elasticity of labor is negative. Therefore, we should enlarge planting areas of soybean. In the view of the current status of China's soybean, planting areas of soybean in the northeast tends to saturate, while the planting areas in the southern region is vast. In addition to paddy fields, there are some other large areas such as mountainous regions, dry fields, tea plantations, orchards and so on. Appropriate intercropping is helpful to increase the planting areas and production of soybean. The no-tillage cropping pattern namede as "wheat - corn - soybean" was proposed (Wenyu Yang, 2006), which has been tested in Sichuan province. It not only expand planting areas of soybean, but also enhance the soybean production. Further researches will be done.

Through the analysis on the factors influencing soybean TFP, techinical achievement, pattern of cultivation, policy have a positive impact on soybean TFP. While the import volume has a negative effect on soybean TFP. Therefore, we should focus on that how to reverse import situation of China's soybean. Meanwhile, we should enhance the ability to breed new varieties, promote techniques of soybean cultivation, speed up technological progress and institutional innovation. For example, providing soybean farmers with subsidies and so on.

\section{References}

CHEN, Weiping. (2006). Productivity Growth, Technical Progress and Efficiency Change in Chinese Agriculture: 1990-2003. Journal of China Rural Survey, 1, 18-23.

Dwight R Sanders, Mark R Manfredo. (2006). Forecasting Basis Levels in the Soybean Complex: A Comparison of Time Series Methods. Journal of Agricultural and Applied Economics, 38(3), 513-524.

HUANG, Wu, WANG, Kai. (2004). Technical Efficiency of Soybean Production in China. Journal of Nanjing Agricultural University (Social Sciences Edition), 4(1), 18-22.

H.Van Den Berg, A.S Lestari. (2001). Improving Local Cultivation of Soybean in Indonesia through Farmers' Experiments. Journal of Expl Agric, 37, 183-193.

HUANG, Jingbo, FU, Jian. (2004). The Empirical Analysis on FDI to Technical Progress in Guangdong. Journal of Management World, 9, 81-86.

Jorge Fernandez-Cornejo, Cassandra Klotz-Ingram. (2002). Farm-level Effects of Adopting Herbicide-tolerant Soybeans in the USA. Journal of Agricultural and Applied Economics, 34(1), 149-154.

Philip M.Fearnside. (2001). Soybean Cultivation As a Threat to the Environment in Brazil. Journal of Environmental Conservation, 28(1), 23-38.

QIN, Fu, SUN, Lipu. (2003). Competitiveness and Strategy of Soybean in China. Journal of Agrotechnical Economics, 5, 39-43.

TIAN, Wei, LI, Mingxian. (2009). The Efficiency Analysis of the Major Soybean Producing Areas in China. Journal of Hunan Agriculture University (Social Sciences), 10(4), 22-26.

WANG, Jimin. (2006). The economics of soybean in China: Emphasis Analysis of Supply and Demand. China: Beijing.

YONG, Taiwen, YANG, Wenyu. (2006). The Cultivating Techniques of Wheat-Corn-Soybean in southern hilly areas. Journal of Crops, 5, 43-44.

YU, Cuiling, FENG, Zhongchao. (2005). Qantitative Analysis on Comparative Advantage and International Competitiveness of Soybean in China. Journal of Research of Agricultural Modernization, 26(1), 26-30.

YU, Jianbin, QIAO, Juan. (2007). Technical Progress and Efficiency Changes of Soybean in China. Journal of Agrotechnical Economics, 4, 41-47.

ZU, Liyi, FU, Xinhong, LI, Dongmei. (2008). The Research on TFP and the Influencing Factors of Plantation in China. Journal of Rural Economy, 5, 51-53. 
Table 1. The results of ADF test

\begin{tabular}{cccccc}
\hline variables & conclusions & Variables $(\mathrm{d})$ & Value of ADF test & p-values & conclusions \\
\hline LNY & steady & LNY $(0)$ & $-3.1218^{* *}$ & 0.0081 & steady \\
LNM & unsteady & LNM(1) & $-5.2752^{*}$ & 0.0002 & steady \\
LNK & unsteady & LNK(2) & $-3.3082^{* *}$ & 0.0070 & steady \\
LNL & unsteady & LNL(1) & $-5.9387^{*}$ & 0.0001 & steady \\
\hline
\end{tabular}

variables(d): the order of difference; $\quad * *$ : significancant responses at the 0.05 probability level;

*: significancant responses at the 0.01 probability level.

Table 2. The egressionresults of factors influencing soybean TFP

\begin{tabular}{lcccc}
\hline variables & coefficient & standard error & T-value & notability \\
\hline constant & 0.1698 & 0.0328 & 5.1808 & 0.000 \\
technical achievement & 0.0015 & 0.0002 & 5.8678 & 0.000 \\
import volume & $-3.18 \mathrm{E}$ & $2.582 \mathrm{E}$ & -12.304 & 0.000 \\
pattern of cultivation & 0.0350 & 0.0084 & 4.1617 & 0.000 \\
policies & 0.0097 & 0.0044 & 2.2306 & 0.000 \\
\hline
\end{tabular}

$\mathrm{R}^{2}=0.95$. Adjusted $\mathrm{R}^{2}=0.93 . \mathrm{F}=54.41$, and it's notable at the level of 0.000 .

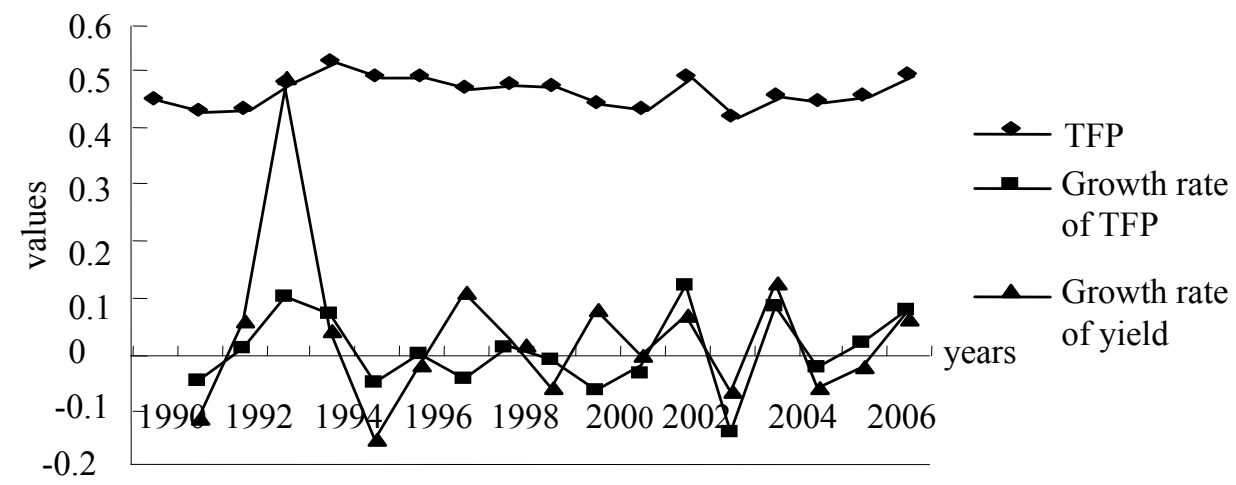

Figure 1. TFP growth rate of China's soybean production and TFP trends 